\title{
MODIFIKASI PATI SUKUN DENGAN METODE IKAT SILANG MENGGUNAKAN TRINATRIUM TRIMETAFOSFAT
}

\author{
Cut Fatimah Zuhra*, Mimping Ginting, Marpongahtun, Ayu Syufiatun \\ Departemen Kimia, FMIPA, Universitas Sumatera Utara, Medan \\ *Alamat Korespondensi: cutfatimah@usu.ac.id
}

\begin{abstract}
Abstrak: Pati alami memiliki aplikasi terbatas karena tidak selalu memiliki sifat yang diinginkan untuk beberapa jenis pengolahan. Oleh karena itu diperlukan modifikasi untuk meningkatkan penggunaan dari pati tersebut, salah satunya dengan melakukan modifikasi pada struktur pati. Penelitian ini bertujuan untuk menghasilkan pati termodifikasi yaitu pati ikat silang fosfat. Pati ikat silang fosfat disintesis dengan mereaksikan pati sukun dengan natrium trimetafosfat dan dilakukan variasi berat natrium trimetafosfat $(1 \%, 2 \%, 3 \%)$ dan waktu reaksi $(30,60$ dan 90 menit). Dari hasil uji yang dilakukan dengan menggunakan spektroskopi IR maka terbentuknya pati fosfat didukung dengan munculnya vibrasi P-O-C pada daerah bilangan gelombang 1050-995 $\mathrm{cm}^{-1}$ dan daerah 1643 $\mathrm{cm}^{-1}$. Pengaruh penambahan konsentrasi trinatrium trimetafosfat dapat meningkatkan nilai derajat substitusi dan menurunkan swelling power. Derajat subtitusi diperoleh berkisar antara 0,2343-0,3003, dimana derajat substitusi yang paling tinggi diperoleh pada penambahan berat natrium trimetafosfat $3 \%$ dan waktu reaksi 60 menit yaitu 0,3003.
\end{abstract}

Kata kunci: pati alami, pati termodifikasi, trinatrium trimetafosfat, derajat substitusi, swelling power

Abstract: Native starch has a limited application because it does not always have the desired properties for certain types of processing. Therefore, modifications of the startch will be needed to improve its use. The objective of this work was to produce a cross-linked starch phosphate. Breadfruit starch was cross-linked with sodium trimetaphosphate (STMP) with concentration variations of $\operatorname{STMP}(1 \%, 2 \%, 3 \%)$ and reaction times (30, 60 and 90 minutes). The formation of cross-linked starch phosphate was analysed by the infrared spectrum with emergence of vibration $\mathrm{P}-\mathrm{O}-\mathrm{C}$ in the area of wave number of 1050-995 $\mathrm{cm}^{-1}$ and $1643 \mathrm{~cm}^{-1}$. The influences of the addition concentration of STMP can increased the value of the degree of substitution and a decrease in the swelling power. The degree of substitution were obtained in a range of 0.2343 to 0.3003 , where the highest degree of substitution obtained at STMP of $3 \%$ and a reaction time of 60 minutes was 0.3003 .

Keywords: native starch, modified starch, sodium trimetaphosphate, the degree of substitution, swelling power

\section{PENDAHULUAN}

Pati adalah bahan baku yang sangat penting untuk industri makanan. Fungsi dari pati sangat dipengaruhi oleh sifat-sifat granular serta molekul pati, kondisi pengolahan dan modifikasi struktur. Pengembangan produk berbahan dasar pati membutuhkan wawasan yang luas agar dapat menghasilkan variasi pati yang diinginkan (Wurzburg 1995).

Pemanfaatan pati di industri sangat luas, baik dibidang pangan maupun non pangan karena kemudahan mendapatkan bahan baku dan harganya yang relatif murah. Namun, beberapa sifat pati alami menjadi kendala apabila digunakan sebagai bahan baku industri, diantaranya sifat pati yang mudah rusak akibat panas dan asam (Sauyana 2014).

Industri penggunaan pati menginginkan pati yang mempunyai kekentalan yang stabil baik pada suhu tinggi maupun rendah, mempunyai ketahanan yang baik terhadap perlakuan mekanis, dan daya pengentalannya tahan pada kondisi asam dan suhu tinggi. Hal tersebut menjadi alasan dilakukan modifikasi pati agar mendapatkan sifat-sifat penting seperti kecerahannya lebih tinggi (pati lebih putih), retrogadasi yang rendah, kekentalannya lebih rendah, gel yang terbentuk lebih jernih, tekstur gel yang dibentuk lembek, swelling power yang rendah, granula pati yang lebih mudah pecah, serta waktu dan suhu gelatinisasi yang lebih tinggi (Koswara 2009).

Buah sukun merupakan salah satu penghasil pati yang cukup popular dan dikembangkan di Indonesia. Buah sukun memiliki kandungan karbohidrat yang tinggi karena itu sukun merupakan salah satu sumber penghasil pati. Pati yang diperoleh dari sukun menghasilkan 18,5 g/100 g dengan kemurnian $98,86 \%$ dan kandungan amilosa $27,68 \%$ dan amilopektin 72,32\% (Rincón \& Padilla 2004).

Modifikasi sifat pati dan teknik pengolahan pati sudah berkembang saat ini, pati alami dapat dimodifikasi sehingga mempunyai sifat-sifat yang lebih baik. Pati taut silang fosfat (PTSF) merupakan salah satu tipe pati termodifikasi yang paling banyak disintesis untuk keperluan industri. Pada skala industri, pati fosfat disintesis menggunakan $\mathrm{POCl}_{3}$ dan campuran garam trinatrium trimetafosfat dan 
trinatrium tripolifosfat dalam suasana basa (Singhal et al. 2008). Pati fosfat dibidang pangan digunakan sebagai bahan pengental, emulsifier dan stabilizier sedangkan di dalam bidang farmasi dapat dimanfaatkan dalam formulasi tablet sebagai pengikat, matriks, bahan pembentuk film untuk penutup luka, pengental dan pensuspensi (Yuliana 2011).

Teja dkk. (2008) melakukan modifikasi pati sagu dengan metode ikat silang menggunakan monosodium fosfat dan menghasilkan peningkatan swelling power dari $8,3245 \mathrm{~g} / \mathrm{g}$ menjadi $38,6066 \mathrm{~g} / \mathrm{g}$ dan derajat substitusi meningkat seiring bertambahnya waktu reaksi.

Romengga dkk. (2011) mensisntesis pati sagu ikatan silang fosfat pada suasana asam menghasilkan derajat substitusi 0,39 dan ukuran granula berkisar 10 $\mu \mathrm{m}$. Variasi suhu dari $25-50^{\circ} \mathrm{C}, \mathrm{pH} 3,0-7,5$, waktu reaksi 10-50 menit, dilakukan dan diperoleh data bahwa reaksi terjadi pada suhu $40^{\circ} \mathrm{C}, \mathrm{pH} 6,5$ dan waktu reaksi 20 menit.

Retnangingtyas dkk. (2014) melakukan modifikasi kimia dengan perlakuan konsentrasi sodium tripolifosfat dan lama perendaman, yang menghasilkan swelling power terbaik pada konsetrasi STTP $1 \%$ dan lama perendaman 1 jam dan solubilitas yang paling baik yaitu pada konsentrasi STTP $0,5 \%$ dan lama perendaman 1,5 jam.

Berdasarkan hal tersebut diatas maka peneliti tertarik untuk mensintesis pati fosfat dari pati sukun dengan menggunakan trinatrium trimetafosfat dengan memvariasikan berat trinatrium trimetafosfat dan waktu reaksi untuk menentukan karakteristik dari pati fosfat.

\section{BAHAN DAN METODE}

\section{Pembuatan Pati dari Buah Sukun}

Metode yang digunakan adalah menggunakan metode pembuatan pati secara umum. Buah sukun dikupas bersih dan dipotong kecil-kecil, kemudian potongan buah dihaluskan menjadi bubur kasar. Bubur ini dicampur dengan sejumlah air bersih lalu diaduk sambil diremas-remas dan disaring dengan kain saringan untuk memisahkan dari ampas. Penyaringan dilakukan berulang kali hingga seluruh pati larut. Pati dibiarkan mengendap dengan memperhatikan lapisan air bagian atasnya. Semakin jernih air berarti pengendapan semakin baik. Setelah air endapan dibuang, pati dikeringkan pada suhu $45^{\circ} \mathrm{C}$ selama 24 jam. Pati yang sudah kering kemudian dihaluskan dan diayak dengan menggunakan saringan mesh 100 .

\section{Pembuatan Pati Ikatan Silang (Pati Fosfat)}

Pati sukun sebanyak 30 g dicampur dengan 45 $\mathrm{mL}$ aquadest sampai terbentuk suspesi, lalu ditambahkan $1 \%$ trinatrium trimetafosfat dan diaduk. Campuran tersebut dibuat $\mathrm{pH} 10$ dengan meneteskan $\mathrm{NaOH} 1 \mathrm{M}$ sambil diaduk. Campuran kemudian dipanaskan pada suhu $45^{\circ} \mathrm{C}$ sambil diaduk selama 30 menit. Selanjutnya bubur pati yang didapatkan dinetralkan sampai sampai $\mathrm{pH}$ 6,5 dengan $\mathrm{HCl} 1 \mathrm{M}$ dan dicuci keseluruhannya. Pati fosfat kemudian dikeringkan pada suhu $40^{\circ} \mathrm{C}$ selama 24 jam. Pati fosfat kasar digiling dan diayak. Prosedur yang sama juga dilakukan untuk berat trinatrium trimetafosfat $2 \%$ dan $3 \%$. Selanjutnya produk dianalisis dengan menggunakan FT-IR dan SEM, Derajat substitusi (DS) dan swelling powernya dihitung. Prosedur di atas dilakukan kembali untuk variasi waktu reaksi yaitu 60 dan 90 menit (Medikasari dkk. 2009).

\section{Derajat Substitusi untuk Pati Ikatan Silang (Pati Fosfat)}

Natrium sulfat sebanyak $1,5 \mathrm{~g}$ dilarutkan dalam 5 $\mathrm{mL}$ aquadest. Setelah itu $2,5 \mathrm{~g}$ sampel pati yang tercrosslinking dilarutkan dalam larutan natrium sulfat tersebut. Sampel kemudian dimasukkan dalam furnace dan dipanaskan pada suhu $550^{\circ} \mathrm{C}$ selama 12 jam untuk diabukan. Sampel yang sudah diabukan dilarutkan dalam larutan $\mathrm{HCl} 25 \%$ dan diaduk hingga larut. Ke dalam larutan tadi ditambahkan aquades hingga volumenya mencapai $50 \mathrm{~mL}$. Dari larutan tadi diambil $10 \mathrm{~mL}$ dan ditambahkan dengan reagen vanadate-molybdate, lalu didiamkan pada suhu ruang \pm 45 menit. Setelah itu sampel diamati dengan menggunakan spektrofotometer pada panjang gelombang $435 \mathrm{~nm}$.

\section{HASIL DAN PEMBAHASAN \\ Pati Ikatan Silang (Pati Fosfat)}

Pati yang digunakan dalam penelitian ini adalah hasil isolasi buah sukun, dimana dari $1 \mathrm{~kg}$ buah sukun diperoleh pati sebanyak $68 \mathrm{~g}(6,8 \%)$. Pati fosfat merupakan hasil reaksi ikat silang antara pati dengan trinatrium trimetafosfat dengan $\mathrm{NaOH}$ sebagai katalis. Pada penelitian ini dilakukan variasi terhadap penambahan berat trinatrium trimetafosfat $1 \%, 2 \%$ dan $3 \%$ dengan waktu reaksi 30 menit. Hasil pati fosfat yang diperoleh di uji derajat substitusinya. Pati fosfat yang memiliki derajat substitusi tertinggi yaitu pada penambahan berat trinatrium trimetafosfat $3 \%(0,2867)$ maka diteruskan untuk mencari waktu yang optimum, adapun variasi waktu yang digunakan adalah 30, 60 dan 90 menit. Terbentuknya pati fosfat ditunjukkan pada hasil analisa FT-IR pada produk dari variasi berat trinatrium trimetafosfat dan variasi waktu yang ditunjukkan dengan munculnya pita serapan pada daerah bilangan gelombang 1050-995 $\mathrm{cm}^{-1}$ yang menunjukkan adanya gugus $\mathrm{P}=\mathrm{O}$ alifatik, yang didukung oleh pita serapan P-O-C asimetrik pada daearah bilangan gelombang 1018,42 $\mathrm{cm}^{-1}$. Pada daerah vibrasi $1643 \mathrm{~cm}^{-1}$ menunjukkan ikatan intramolekul hidrogen, pada pati sukun puncak 1643 $\mathrm{cm}^{-1}$ muncul lebih tajam daripada pada pati terikat silang posfat, ini menunjukkan sudah terjadinya pemutusan ikatan hidrogen sehingga gugus $\mathrm{OH}$ terkonversi menjadi ester fosfat (Liu et al. 2014). Bilangan gelombang 3425 masih muncul pada spektrum IR pati fosfat dikarenakan belum semua 


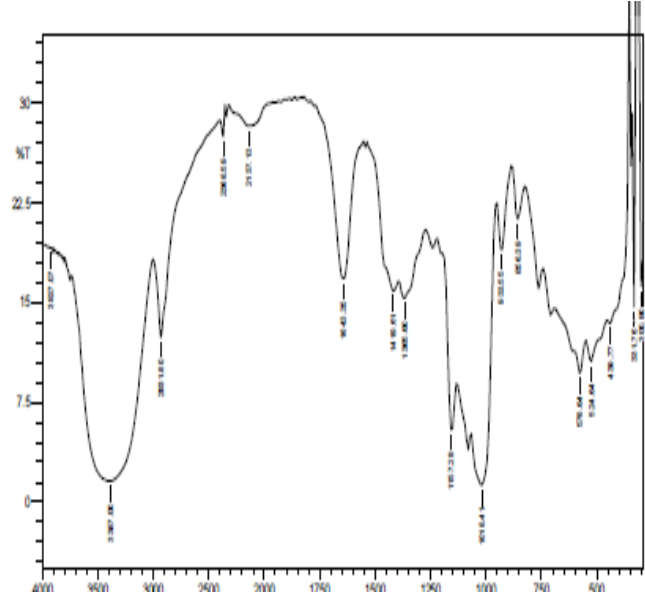

(a)

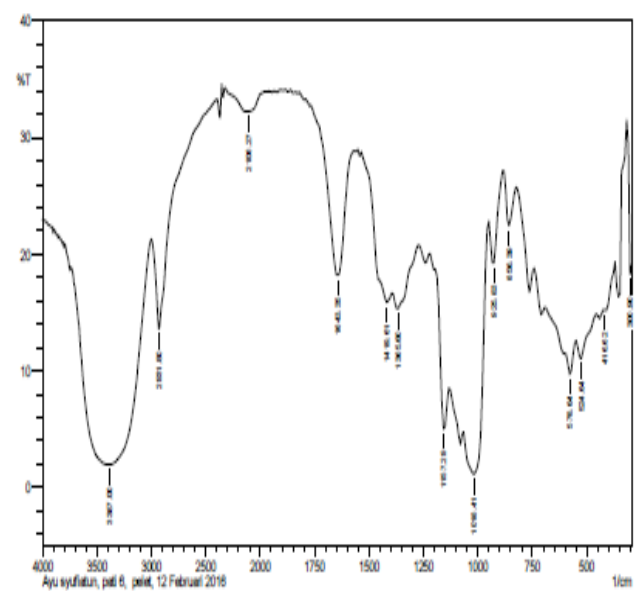

(c)

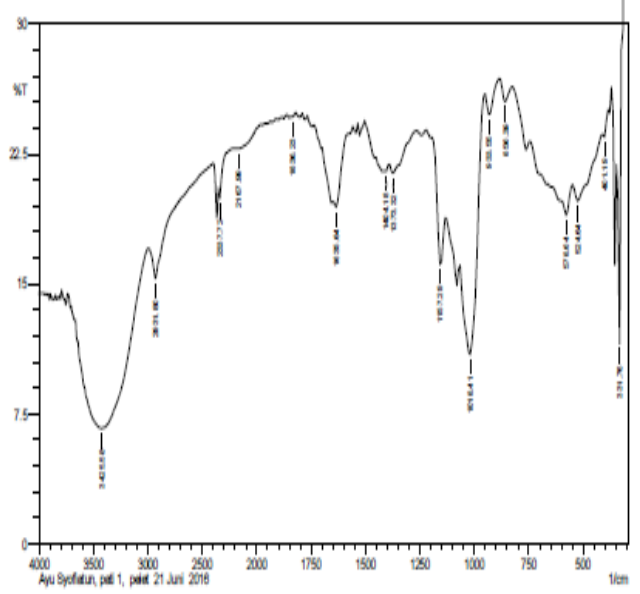

(e)

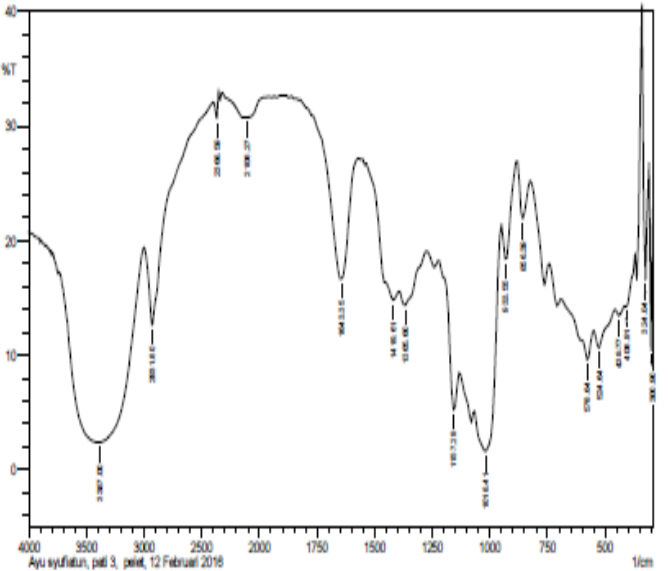

(b)

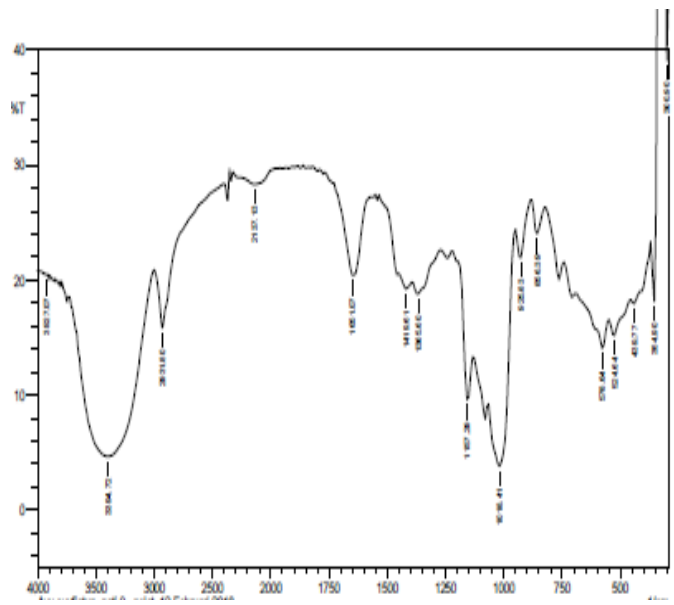

(d)

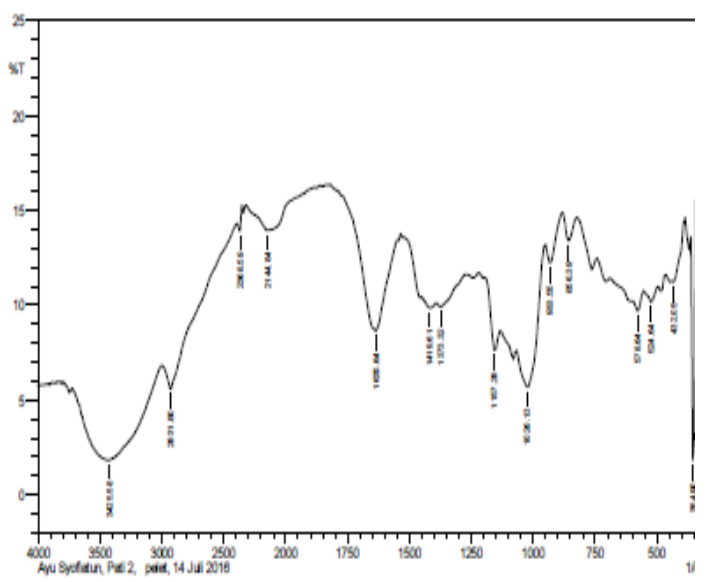

(f)

Gambar 1. Spektrum FT-IR (a) Pati dan Pati Fosfat dengan dengan variasi (b) berat STMP 1\%, (c) berat STMP 2\%, (d) berat STMP 3\% / 30 menit (e) 60 menit, (f) 90 menit

$\mathrm{OH}$ tergantikan oleh fosfat, hal ini dapat dilihat dari nilai derajat substitusi yang masih dibawah 3 . Spektrum dapat dilihat pada Gambar 1 untuk variasi penambahan berat trinatrium trimetafosfat dan waktu reaksi.

\section{Derajat Substitusi Pati Pati Fosfat}

Pati posfat yang didapat dari hasil reaksi dengan variasi penambahan berat trinatrium trimetafosfat dan waktu dihitung derajat substitusinya dengan menggunakan spektrofotometer UV-VIS. Hasil derajat substitusi untuk variasi penambahan berat 
trinatrium trimetafosfat dan waktu reaksi dapat dilihat pada Tabel 1.

Tabel 1. Derajat substitusi pati fosfat dengan variasi penambahan trinatrium trimetafosfat (STMP) dan waktu

\begin{tabular}{lcc}
\hline \multicolumn{1}{c}{ Perlakuan } & $\begin{array}{l}\text { Persen } \\
\text { Fosfat }\end{array}$ & DS \\
\hline STMP 1\% & 3,8299 & 0,2343 \\
\hline STMP 2\% & 3,9801 & 0,2451 \\
\hline STMP 3\%/ 30 menit & 4,5392 & 0,2867 \\
\hline 60 menit & 4,7156 & 0,3003 \\
\hline 90 menit & 3,9050 & 0,2396 \\
\hline
\end{tabular}

Uji kadar fosfat dan derajat subtitusi digunakan untuk mengetahui berapa banyak gugus fosfat yang tersubtitusi kedalam pati sukun. Pada penelitian ini hasil derajat substitusi yang diperoleh berkisar antara $0,2343-0,2867$. Dimana hasil derajat subtitusi yang tertinggi yaitu 0,2867 berasal dari pati fosfat dengan variasi penambahan berat trinatrium trimetafosfat 0,3 g (3\%). Pembuatan pati fosfat dipengaruhi oleh banyaknya agen pengikat silang yang digunakan. Hal ini disebabkan karena semakin banyak trinatrium trimetafosfat yang digunakan maka semakin banyak gugus fosfat yang dapat mensubstitusi gugus $\mathrm{OH}$, karena melemahnya ikatan hidrogen.

Tabel 2. Swelling Power Pati Posfat

\begin{tabular}{cccccc}
\hline $\begin{array}{c}\text { Waktu } \\
\text { (Jam) }\end{array}$ & STMP 1\% & STMP 2\% & $\begin{array}{c}\text { STMP 3\%/ } \\
30 \text { menit }\end{array}$ & 60 menit & 90 menit \\
\hline 6 & $1,07 \%$ & $0,66 \%$ & $0,89 \%$ & $0,26 \%$ & $0,96 \%$ \\
12 & $2,52 \%$ & $3,09 \%$ & $1,83 \%$ & $0,61 \%$ & $1,79 \%$ \\
24 & $4,32 \%$ & $3,45 \%$ & $3,27 \%$ & $1,11 \%$ & $3,69 \%$ \\
48 & $4,54 \%$ & $3,91 \%$ & $3,41 \%$ & $1,48 \%$ & $4,05 \%$ \\
72 & $5,03 \%$ & $4,23 \%$ & $4,13 \%$ & $1,74 \%$ & $5,83 \%$ \\
\hline
\end{tabular}

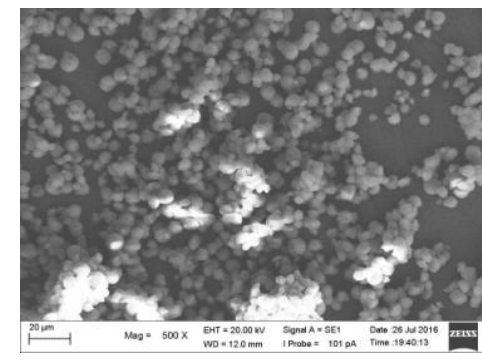

(a)

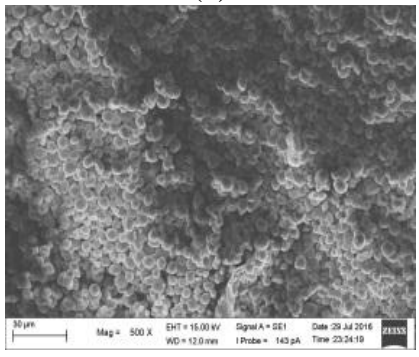

(c)

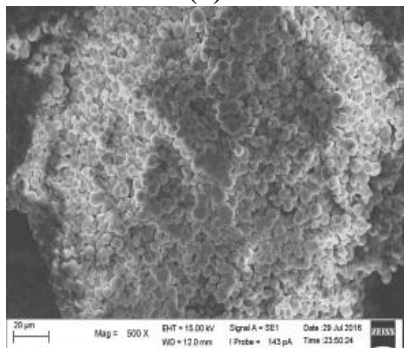

(e)

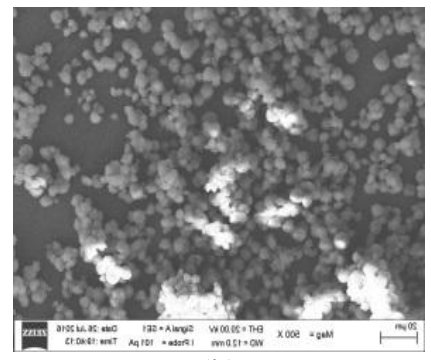

(b)

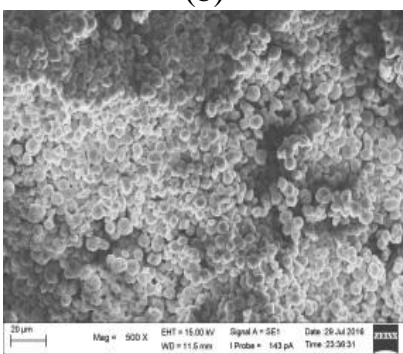

(d)

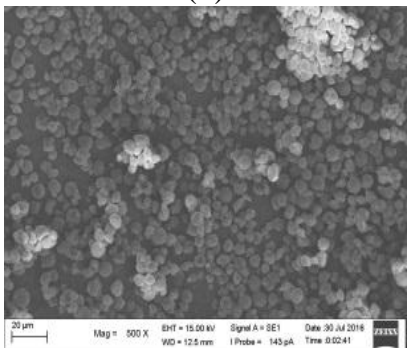

(f)

Gambar 2. Morfologi permukaan (a) pati dan pati fosfat dengan variasi (b) berat STMP 1\%, (c) berat STMP $2 \%$, (d) berat STMP 3\% / 30menit (e) 60 menit, (f) 90 menit. 


\section{Swelling Power Pati Fosfat}

Swelling power yang diperoleh dari hasil penelitian ini dapat dilihat pada Tabel 2. Dari hasil penelitian yang dilakukan didapatkan persen swelling power yang meningkat seiring bertambahnya waktu absorbsi. Dilihat dari Tabel 2, swelling power terendah diperoleh pada penambahan STMP 3\% dan waktu reaksi 60 menit, hal ini disebabkan karena semakin banyak terbentuk ikatan silang fosfat dengan molekul amilosa didalam granula pati maka menyebabkan pembengkakan menjadi terbatas. Hal ini juga dipengaruhi oleh adanya rongga pada pati fosfat yang dibentuk oleh ikatan silang, sehingga molekul air akan terikat pada rongga tersebut.

\section{Morfologi Permukaan Pati Sukun Posfat}

Analisis SEM dilakukan untuk melihat morfologi dari hasil modifikasi pati yang diperoleh, hasil dapat dilihat pada Gambar 2.

Bentuk morfologi pati sukun yang diperoleh dari hasil variasi yang dilakukan berbentuk granulagranula, dan memberikan hasil yang tidak jauh berbeda. Hal ini menunjukan bahwa penambahan trinatrium trimetafosfat tidak mempengaruhi bentuk granula pati.

\section{KESIMPULAN}

Pati fosfat dapat disintesis melalui reaksi ikat silang antara pati sukun dengan trinatrium trimetafosfat. Analisis Pati fosfat menggunakan FTIR menunjukka adanya vibrasi P-O-C pada daerah bilangan gelombang 1050-995 $\mathrm{cm}^{-1}$ dan daerah 1643 $\mathrm{cm}^{-1}$. Dari hasil penelitian diperoleh informasi bahwa kondisi optimun reaksi adalah pada penambahan berat STMP 3\% dan waktu 60 menit.

\section{Ucapan Terima Kasih}

Penulis mengucapkan banyak terimakasih pada Dirjen Dikti Yang telah membiayai riset ini melalui Program Hibah Bersaing tahun anggaran 2016. Dan kepada semua pihak yang telah membantu pelaksanaan penelitian ini.

\section{DAFTAR PUSTAKA}

Koswara, S. (2009). Teknologi Modifikasi Pati. Ebookpangan.com
Liu, J., Wang, B., Lin, L., Zhang, J., Liu, W. \& Zie, J. (2014). Functional physicochemical properties and structure of cross-linked oxidized maize starch. Food Hidrocolloids. 36: 45-52.

Medikasari, Nudjanah, S., Yuliana, N. \& Lintang, N. (2009). Sifat amilografi pasta pati sukun termodifikasi menggunakan sodium tripolifosfat. Jurnal Teknologi dan Industri Hasil Pertanian. 14(2): 173-177.

Retnaningtyas, D.A. \& Putri, W.D.R. (2014). Karakterisasi sifat fisikokimia pati ubi jalar oranye hasil modifikasi perlakuan STPP (lama perendaman dan konsentrasi). Jurnal Pangan dan Agroindustri. 2(4): 68-77.

Rincón, A.M. \& Padilla, F.C. (2004). Physicochemical properties of Venezuelan breadfruit (Artocarpus altilis) starch. Archivos Latinoamericanos de Nutricion. 54(4): 449456.

Romengga, J., Irawadi, T.T., Djulaika, R., Muntamah \& Zakaria, A., 2011. Sintesis pati sagu ikatan silang fosfat berderajat substitusi fosfat tinggi dalam suasana asam. Jurnal Teknologi dan Industri Pangan. 22(2): 118-124.

Sauyana, Y. (2014). Produksi pati asetat dengan menggunakan pati sagu nanokristalin. Skripsi. Departemen Teknologi Ilmu Pertanian FTP, IPB, Bogor.

Singhal, R.S., Kennedy, J.F., Gopalakrishnan, S.M., Kaczmarek, A., Knill, C.J. \& Akmar, P.F., (2008). Industrial production, processing, and utilization of sago palm-derived products. Carbohydrate polymers. 72(1): 1-20.

Teja, A., Sindi, I., Ayucitra, A. \& Setiawan, L.E.K. (2008). Karakterisasi pati sagu dengan metode modifikasi asetilasi dan cross-linking. Jurnal Teknik Kimia Indonesia. 7(3): 836-843.

Wurzburg, O.B. (1989). Modified Starch : Properties and Uses. Boca Raton: CRC Press.

Yuliana. 2011. Karakteristik Pragelatinasi Pati Singkong Fosfat yang Dibuat dengan Menggunakan Natrium Tripolifosfat sebagai Ekspisien dalam Sedian Farmasi. Skripsi. Program Sarjana Farmasi FMIPA, UI. 